\title{
RAFAEL ESTRADA Y LA DISTINCIÓN EN EL CAMPO LITERARIO COSTARRICENSE DE LA DÉCADA DE 1920
}

Francisco Rodríguez Cascante

\section{(9) $(1) \Theta$}

Esta obra está bajo una licencia Creative Commons

Reconocimiento-No Comercial-Sin Obra Derivada 



\title{
RAFAEL ESTRADA Y LA DISTINCIÓN EN EL CAMPO LITERARIO COSTARRICENSE DE LA DÉCADA DE 1920
}

\author{
RAFAEL ESTRADA AND HIS DISTINCTION WITHIN THE \\ LITERARY FIELD IN COSTA RICA IN THE 1920S
}

\author{
Francisco Rodríguez Cascante
}

\begin{abstract}
RESUMEN
A partir de los postulados teóricos de Pierre Bourdieu acerca de los campos culturales, se analiza la polémica que en la década de 1920 sostuvo Rafael Estrada Carvajal, el poeta introductor de la literatura vanguardista en Costa Rica, con los agentes poseedores de mayor capital cultural del campo literario costarricense de la época. Se argumenta que en tal lucha por el poder de distinción, la obra del joven autor, por estar conformada por una heterogeneidad que dialogaba tanto con la tradición modernista como con las vanguardias, y consecuente era distante del canon tradicional, fue relegada a una zona periférica del campo literario, desplazamiento que se mantiene hasta la actualidad.

Palabras clave: campo cultural, historia literaria, literatura costarricense, poesía, Rafael Estrada.
\end{abstract}

\begin{abstract}
Based on the theoretical statements by Pierre Bourdieu regarding cultural fields, I analyze the problem argued by Rafael Estrada Carvajal in the 1920s with those agents whom possessed the greatest cultural knowledge in regards to literature in those times; he was the first poet to introduce the state-of-the-art (Vanguard) literature in Costa Rica. It is argued that in the fight for power of distinction, the literary works by the young writer, given that it was characterized by a heterogeneity which dialogued with the modernist tradition as well as with the Vanguard ones, hence stayed detached from the traditional canon; it was given to a peripheral realm in the literary world, a displacement which is true to this day.

Key words: Cultural realm, literary history, Costa Rican literature, poetry, Rafael Estrada.
\end{abstract}

\section{Introducción}

En un estudio publicado en 1979, Carlos Rafael Duverrán señalaba que no existió un movimiento vanguardista en la poesía costarricense de la década de 1930, antes bien, solo brotes aislados que no lograron cuajar en una obra madura, y que en los escritos de Rafael

Dr. Francisco Rodríguez Cascante. Universidad de Costa Rica. Catedrático en la Sede de Occidente. Costa Rica. Correo electrónico: francisco.rodriguezcascante@ucr.ac.cr

Recepción: 20- 02- 2017

Aceptación: 20- 05- 2017 
Estrada, Adilio Gutiérrez y Max Jiménez lo que se presentaron fueron intentos de libertad postmodernista. Tal hipótesis lo lleva a concluir que la década de los 30 fue "de gran pobreza lírica" (1979, p. 215). Esta supuesta ausencia de madurez certificada por la hibridez entre lo moderno y lo "que siguió" (pos), antes que la ansiada solidez de un movimiento literario fuertemente anclado, es el reclamo que no solamente una gran parte de la crítica de las últimas décadas del siglo XX, sino también la contemporánea a Estrada, le han hecho al autor, y han provocado no solo desatención a sus escritos, sino que lo han conducido a un injustificable olvido.

En este artículo, se procura demostrar que este principio de exclusión operó en el marco del joven campo literario costarricense de las primeras décadas del siglo XX, como una encarnizada lucha entre los agentes dominantes y aquellos que procuraban ocupar un mayor espacio. En este sentido, la disputa por el principio de distinción del objeto artístico (Bourdieu, 1998) dentro del campo cultural costarricense de la época generó no solamente la censura para Estrada y su obra, sino también su ubicación en una difusa zona centrífuga que ha acarreado el tachamiento de su pionero trabajo literario. Tal disputa es el objeto de interés de este artículo, la cual se produjo básicamente en la prensa del momento.

\section{Campo literario y control semiótico}

A inicios de la década del noventa, en Las reglas del arte. Génesis y estructura del campo literario, Pierre Bourdieu planteó que la producción y la recepción de los textos estéticos en general se articulan en campos de poder, los cuales constituyen espacios de relaciones de fuerza entre agentes o instituciones que tienen en común poseer el capital necesario para ocupar posiciones dominantes en tales campos.

Con este planteamiento, el autor indicaba que era posible superar la oposición entre lectura interna y análisis externo sin perder nada de los aportes de ambos enfoques, y más bien se recuperaba la dimensión relacional propia del concepto de intertextualidad. A partir de esta afirmación, propuso la hipótesis de la existencia de una "homología entre el espacio de las obras definidas en su contenido propiamente simbólico, y en particular en su forma, y el espacio de las posiciones en el campo de producción." (1995, p. 308). Esto lo llevó a señalar que debido a las homologías entre el campo literario y el campo de poder (campo social en su conjunto) la mayor parte de las estrategias literarias están sobredeterminadas y sus elecciones son golpes estéticos y políticos al mismo tiempo, es decir tanto internos como externos.

Antes de este trabajo, ya en La distinción de 1979, Bourdieu había propuesto que "el objeto artístico es la objetivación de una relación de distinción y que por ello está expresamente predispuesto a soportar, en los contextos más diferentes, tal relación.” (1998, p. 224). En esas luchas simbólicas a lo interno de los campos, los agentes se disputan ese principio de distinción que los diferencia ya sea como productores o consumidores de los bienes artísticos. De esta manera, "toda apropiación de una obra de arte, que es una relación de distinción realizada, hecha cosa, es a su vez una relación social y, contra la ilusión del comunismo cultural, una relación de distinción.” (1998, p. 225). Este vínculo implica la exclusión de aquellos bienes simbólicos que nos son valorados como estéticos.

La distinción que otorga el poder dentro de los campos otorga la convicción, y por ende el placer, de la seguridad de la creencia, la illusio, es decir, la "adhesión originaria al juego literario que fundamenta la creencia en la importancia y en el interés de las ficciones 
literarias" (1995, p. 483). Estos principios de distinción e illusio son los que determinan las batallas por el control de los significados y su valor tanto en la esfera intra-literaria como en la circulación de los textos dentro de los campos culturales.

En el caso de Rafael Estrada, es notorio el conflicto entre los agentes establecidos del campo literario costarricense de la segunda década de 1920 y un artista advenedizo que procuró socavar los principios de distinción e illusio de dichos agentes. La polémica puso en evidencia no solo estas disputas entre agentes, sino también entre dos modelos estéticos que se enfrentaban a lo interno del campo literario pero también a lo externo, en el espacio de la legitimidad del campo cultural.

\section{El detonante del conflicto: Huellas}

La publicación del poemario Huellas en 1923 fue el detonante de estas disputas, porque el texto proponía un tipo de poesía distinta a la legitimada. Pero ¿quién era ese joven iconoclasta de tan solo veintidós años que se atrevió a escribir sin seguir el canon modernista ortodoxo que dictaba un estricto apego a las normas formales del ritmo y la métrica?

Rafael Estrada Carvajal nació en Sonsonate, El Salvador, el 12 de marzo de 1901, hijo de Rafael Estrada Salas (primo hermano del poeta Félix Ángel Salas) y de Julia Carvajal Mora, maestra. La pareja se había trasladado a El Salvador por motivos laborales, pero regresaron a San Ramón en el año 1905.

Violinista desde niño, cursó sus estudios primarios en San Ramón de Alajuela y se trasladó luego a efectuar estudios a la Escuela Normal de Heredia, donde se graduó como docente. Luego se tituló, también, como pasante de Derecho.

En 1927 realizó una gira por Centroamérica y México, donde conoció al pintor Diego Rivera. Las experiencias vividas en este país las elaboró en una parte destacada de su obra poética ${ }^{1}$. Murió muy joven víctima de un accidente con arma de fuego en $1933^{2}$.

Estrada Carvajal laboró como profesor de psicología y lógica en el Liceo de Costa Rica en la segunda parte de la década de $1920^{3}$. Su breve existencia de tan solo treinta y dos años le posibilitó publicar tres poemarios; además de Huellas: Viajes sentimentales (1924) y Canciones y ensayos (1929); y un breve ensayo: Los estudios estéticos (1925).

Huellas es un poemario extenso y ambicioso, cuidadosamente trabajado y editado. El libro está conformado por tres partes. La primera se encuentra compuesta por lo que el autor denominó "épocas", cuatro en total, cada una con un nombre: "El deseo", "Reflexiones", "Introspección” y "Orientación". A esta primera parte suceden "Pétalos caídos" y "Otros motivos". En total, el documento está conformado por noventa y ocho poemas, más dos textos introductorios: un "Liminar" escrito por el filósofo y novelista Moisés Vincenzi ${ }^{4}$, Director de las Ediciones Popol Vuh de la Editorial Borrasé, donde se publica el poemario, y una carta de Marco Aurelio Zumbado, Presidente del Centro Intelectual Editor a Vincenzi en la cual se refiere al texto de Estrada. Además de estos documentos liminares, al final del texto se presenta un poema de Carlos Luis Sáenz y otro del mismo Estrada que titula "Post Libris".

Como se observa, el libro procura un fuerte estatuto de legitimación. En el "Liminar", Vincenzi pretende establecer que el poemario es antes que nada una profunda reflexión filosófica sobre la condición humana. Si bien reconoce que el poeta "tiene rebeldías profundas" (1923, p. 5), "ha roto ya con las complicidades del medio" (1923, p. 5) y es portador de un "estilo incipiente" (1923, p. 5), destaca que "buscando extremos estéticos ha encontrado 
filones metafísicos explotables" (1923, p. 5) y, al mismo tiempo, es un explorador que huye de las superficialidades de la lengua logrando el sentido estético, al igual que la exactitud en la expresión psicológica. Todo ello lo lleva a plantear que la lectura de Huellas conduce a sentir "emociones cósmicas" (1923, p. 9), si bien "Cierta levedad aristocrática falta a su léxico y a su sintaxis" (1923, p. 10).

Uniéndose a estos elogiosos criterios de Vincenzi, Marco Aurelio Zumbado expresa que, efectivamente "Hay mucho en esos versos que la filosofía puede analizar con más conciencia que la crítica" (1923, p. 12), puesto que estima que Estrada representa muy bien a la época cambiante que vive.

Por su parte, Carlos Luis Sáenz, también defensor de Estrada, en "Renuncia a los motivos", poema ubicado al final del texto, le dice al poeta que se aleje de la tradición y siga sus impulsos, puesto que no existe nada fijo en la estética: "Renuncia a los motivos y ama la simple forma / que tu alma te evidencia! Así será tu norma / eterna como la honda del mar siempre cambiante!" (1923, p. 174). Estrada se hace eco de este llamado de Sáenz, ya que inmediatamente después, y como cierre del poemario, colocó la composición "Post Libris", en cuya primera estrofa dice abandonar la tradición y seguir sus propios designios: "Si el alma es universal, / y yo he oído a mi alma, / y he expresado lo que mi alma dice, / impórtanme poco los siglos / y los hombres de la barbarie." (1923, p. 175).

Sin embargo, a pesar de este aparato de legitimación editorial, en su primera recepción, la crítica se dividió. Mientras algunos defendían el texto, la mayoría lo censuraba de una manera contundente.

Uno de los primeros en valorar positivamente el libro fue el poeta y narrador José Francisco Villalobos ${ }^{5}$, quien equipara la obra de Estrada, por un lado, con las de figuras cumbre del pensamiento como Nietzsche y Martí, y por otro lado, con la escuela del postumismo dominicano. Dice Villalobos:

\footnotetext{
Viene ahora que, ya en Costa Rica otro poeta, Rafael Estrada, se ha iniciado en la escuela del Postumismo. Este poeta sí responde a las aspiraciones que reclama el fundamento de la nueva escuela. Hondo poeta, la factura de su verso -de cierta melancolía indostánica- obedece a un plano completamente metafísico. Rigorista de la forma al mismo tiempo que poeta filósofo, Rafael Estrada sabe que el oído gusta del vocablo sonoro y, aunque incurriendo en no pocos errores del verso quebrado [...] logra el paralelo con Federico Nietzsche. (1924, p. 2)
}

No obstante, la crítica negativa fue la predominante. Uno de los que más incisivamente atacó el libro fue Juan de la Cruz, quien señaló en un comentario publicado en el Diario de Costa Rica, el 14 de febrero de 1924, que en las doscientas y pico de páginas del libro no había encontrado ni un solo verso: "Y eso es este libro: un infundio de muy mala prosa dividida en renglones cortos." (1924, p. 3). Al final de sus comentarios descalificativos, se pregunta escandalizado: "¿pero, es que ha degenerado tanto el verso? Estamos en pleno bolcheviquismo poético. ¿Es para cantado en un verso lo de que abren un chorro de agua y que un criado pasa y canta?" (1924, p. 3).

De la Cruz se lamenta de que en Huellas no se encuentre ni ritmo ni medida, y que se aleje el escrito de la verdadera concepción del verso ${ }^{6}$. En este sentido, el crítico estima que el poemario de Estrada es un conjunto de incoherencias expresadas en un muy elemental lenguaje prosaico que realmente contraviene toda noción de estética.

El 16 de febrero de 1924, Vincenzi vuelve a la defensa de Estrada y publica en el mismo periódico un artículo denominado "Carta a Rafael Estrada". Ahí le indica que Huellas 
ha despertado serias preocupaciones estéticas y que la crítica no ha comprendido que se trata de una poesía escrita "fuera de toda ritualidad formalista" $(1924$, p. 7) y que tal incomprensión se debe a que él está proponiendo por primera vez en Costa Rica el problema del subjetivismo trascendente en la poesía.

Ante tales cuestionamientos, Vincenzi le aconseja a Estrada que haga una divulgación de sus propuestas como reacción ante el medio tan mezquino que le achaca el alejarse de las más elementales normas de la creación literaria: "Haga usted, querido poeta, un poderoso ensayo de propaganda de estas ideas modernísimas a que usted debe su robusta personalidad poética. Emprenda una lucha tenaz contra los organilleros de la sílaba. Y aunque la literatura parezca estar cansada de tanta escuela, haga la suya si usted se siente con fuerzas para hacerla." (1924, p. 7).

Al día siguiente de la carta de Vincenzi, Pedro Cruz publica, también en el Diario de Costa Rica, un artículo titulado "Examen y crítica de ingenios", en el cual indica que la nota del filósofo no es más que un texto para consolar a Estrada de las fundadas críticas hechas por Juan de la Cruz, en el sentido de que el libro de Estrada no está escrito en verso, debido a este género literario requiere necesariamente del ritmo y la métrica como condiciones ineludibles. Por ello, el articulista argumenta: "Creo que haría mejor Vincenzi, antes de poner humo de trascendencias en los ojos de Estrada, aconsejarle o que siga la senda de los grandes maestros, obediente, o que busque la prosa, pues ni exceptuamos el corte -hecho para que no digan- de los renglones, no otra cosa resultan sus Huellas." (1924, p. 2).

El encono de varios agentes del campo cultural los llevó a efectuar un procedimiento muy común en la época: la publicación, mediante seudónimo, de poemas con intención satírica que supuestamente imitaban el estilo libre. El objetivo de estos textos fue mostrar que el estilo de la "nueva poesía" era simple y ridículo. Uno de los ejemplos más representativos de esta orientación es la publicación del poema "Huellas de la semana", por alguien que utilizó el pseudónimo "Penélope"7. El interés de este texto es señalar que la inconformidad con los textos estradianos no radicaba en su analogía con la estética modernista, sino con las nuevas, desconocidas y temidas corrientes vanguardistas, con las cuales asociaban la poesía de Estrada. El texto pretende la ridiculización de un tipo de poesía que su autor vincula con el facilismo constructivo:

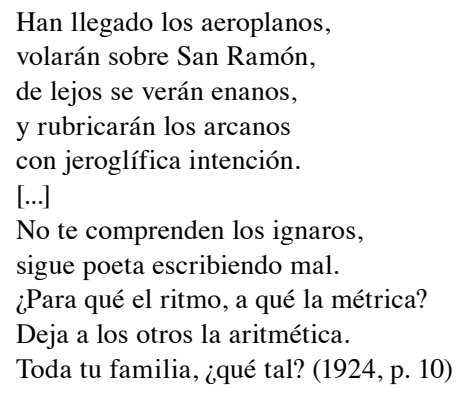

La referencia al aeroplano, típica citación de las vanguardias ortodoxas, especialmente del futurismo, constituye clara referencia a esa renovación de la poesía que Saúl Yurkievich cataloga como representación de la "mutabilidad incesante de la urbe moderna." (1982, p. 352). De esta manera, estos textos paródicos ponen en evidencia que lo que estaba en juego, era tanto un fenómeno a lo interno de la escritura poética, puesto que se cuestionaba la tradicional regla 
de formalidad métrica y rítmica, como a lo externo, en el sentido de que este tipo de literatura, que tenía claros referentes internacionales (las vanguardias europeas y latinoamericanas), se oponía a la distinción de los agentes del campo literario más legitimados del momento.

La reacción defensiva de Estrada no se hizo esperar y la dio en tres frentes: a) publicar como suyos poemas de un poeta muy reconocido, b) demostrar que "su estilo" formaba parte de las técnicas de la poesía contemporánea, y c) polemizar con los agentes más poderosos del campo cultural.

En el primer frente de batalla, Estrada publicó en abril de 1924, en el Diario del Comercio, una sección titulada "De la farándula diaria", donde dio a conocer algunos textos de un supuesto libro que tenía en prensa denominado La sonrisa del sendero. Ahí publicó los poemas breves "La obra", "Canción espiritual", "Luz", "El pajarito verde", "Elasticismos", "Presencia", "Madrugada" y "Pasión", con la finalidad de provocar a los lectores que lo rechazaban. En dicha sección señala: “¿Me atacan, me censuran?, pues ahí tienen. Y que no sigan porque seguiré publicando libros: El credo del caminante, La luz de un túnel durante la noche, La obscuridad del mediodía pletórico de sol, y otros volúmenes que ya tengo escritos. Solo espero nuevos reproches para echarlos afuera. ¡Y que se tengan!” (1924, p. 5). El tono confrontativo y la ironía ante sus críticos traspasaba ya el nivel de la discusión mínimamente mesurada.

Seguidamente, Estrada espera la reacción de los críticos y en el periódico La Tribuna del 6 de mayo de 1924 confiesa que realmente los poemas son de Juan Ramón Jiménez, específicamente de su libro Belleza (1923). Con actitud polémica y aguerrida explicita que los más de los lectores se "han manifestado absolutamente torpes e ignaros. Como ochenta artículos han salido contra mí, que han desternillado de risa a la Costa Rica que lee periódicos. Yo me conformo ahora con que el turno de reírse me toque a mí con esta sola publicación." (1924, p. 7). Finaliza indicándole al director de La Tribuna que queda conforme con la condena que le hacen, porque la comparte con el laureado poeta español.

Queda claro que desde las primeras críticas a Huellas, Estrada no se sintió intimidado por sus críticos, antes bien, se mostró inclaudicable en la defensa de un tipo de poesía que iba a contracorriente con el imaginario poético dominante en la Costa Rica de la segunda década del siglo XX. Aguerrido, polemista, irónico y sarcástico, Estrada enfrentó con pundonor a quienes quisieron ridiculizarlo por su juventud y su estilo poético.

La segunda estrategia que empleó el autor fue argumentar que sus concepciones literarias no eran simples caprichos individuales, sino que formaban parte de una nueva concepción estética que era ampliamente reconocida a nivel internacional. Por ello, se aventuró en una misión pedagógica que procuraba dos objetivos. El primero fue desafiar a los escritores que lo adversaban a que explicaran las determinaciones métricas y rítmicas de la nueva poesía que incorporaba el versolibrismo y otras combinaciones métricas. Esto lo hizo en un artículo del 3 de noviembre de 1927. En él señaló: "Quiero demostrar al público que ninguno de los que aquí se ufanan de reírse del modernismo, 'Ninguno', NINGUNO, conoce ni los comienzos del movimiento modernista." (1927, p. 3). Indica que los inicios de este movimiento corresponden a una poesía "neo-clásica", lo cual tampoco, según su criterio, es sabido por aquellos a quienes llama "infelices medidores de versos y decidores de falsedades" (1927, p. 3). Por ello, los reta a que expliquen en el periódico los empleos formales de reconocidos autores modernistas, como Darío, Nervo, Velarde, y otros destacados poetas latinoamericanos. Indica, también, que si son capaces de hacerlo apropiadamente, él dejaría de escribir. Ninguno de sus críticos asumió el reto.

El segundo objetivo fue, con base en la crítica objetiva, dar a conocer las técnicas de la poesía moderna. Con este propósito, publicó, el 23 de noviembre de 1927, el artículo "Métrica 
moderna. Primeros ejemplos para el conocimiento de la técnica de la poesía contemporánea". Convencido de que lo que reinaba en el país era el desconocimiento, Estrada se propuso argumentar que después de treinta años de modernismo la poesía había cambiado al igual que sus normas métricas, sin que ello implicara que la transformación era errónea.

De esta forma, para Estrada lo que acontecía era que la escritura poética contemporánea no correspondía con los viejos criterios de la valoración crítica, por lo cual se imponía la necesidad de estudiar las nuevas formas para determinar los cambios. Con base en ello, plantea la existencia de una "métrica antigua" frente a las innovaciones de la "actual". Esta última, por ejemplo, mezclaba versos de once sílabas con aquellos de trece, siete y nueve. Tal asunto lo considera el autor con base en estrofas de Moreno Villa, Amado Nervo y Brenes Mesén.

Rafael Estrada intentó, como sostiene Eduardo Uribe (1929, p. 357), enseñarles a los costarricenses de su tiempo la forma científica de considerar la métrica "nueva", para que pudieran valorar las más recientes manifestaciones artísticas. Sin embargo, se preguntó Uribe, ¿qué consiguió el poeta al intentar educar el gusto artístico de sus coterráneos? La respuesta fue que nada o muy poco, porque, en realidad sus compatriotas tenían educado un gusto estético que articulaba un tipo de distinción: la que les proporcionaba el consenso de la illusio por la estructura poética que vinculaba verdad, bondad y belleza, herencia muy prestigiosa, todavía, del siglo XIX.

La tercera estrategia fue la más compleja, y donde se aprecia un mayor desplazamiento del ámbito interno de la composición literaria hacia el exterior de la vida social y los mecanismos de funcionamiento del campo cultural y del poder de sus agentes. Consistió en la virulenta polémica que enfrentó el arte tradicional de raigambre decimonónica con el experimentalismo del arte moderno.

\section{Los pecados modernistas: la polémica sobre el arte nuevo}

Un año antes de la publicación de Huellas, el escritor Carlos Luis Sáenz dio a conocer en el Repertorio Americano una selección de seis poemas de Estrada, y se refirió a su lenguaje como "original y simbólico, nuevo en la forma, hondo y sugestivo en la idea, inquietante por la futura creación a que servirá" (1922, p. 4), comentarios que no fueron bien recibidos por los agentes dominantes del incipiente campo literario costarricense ${ }^{8}$.

En defensa de una estética experimental, inmersa en la hibridación entre el intimismo postmodernista y la vanguardia literaria, y, por tanto, alejada de los cánones formales y retóricos del clasicismo, Rafael Estrada sostuvo, como tercer frente de batalla, una permanente disputa con los agentes legitimados de la tradición literaria heredera del romanticismo. Tal situación llegó a altos niveles de encono que trascendieron la valoración textual y se orientaron a la dimensión personal, poniendo en evidencia que la discusión transitaba entre lo interno y lo externo del campo literario; del seno de las estructuras textuales a su circulación e illusio en el campo social. Quienes más profesaron malestar con Estrada fueron dos de las más importantes figuras del campo literario nacional de la década de 1920: Napoleón Quesada, quien fue director del Liceo de Costa Rica y Ministro de Educación Pública durante la segunda administración de Ricardo Jiménez; y Rogelio Sotela, miembro de la Academia Costarricense de la Lengua, diputado al Congreso, gobernador de San José y el primer historiador de la literatura costarricense.

En 1925, Quesada se expresaba de la siguiente manera del autor de Viajes sentimentales en un artículo relativo al examen de la poesía costarricense contemporánea: 
[...] puedo afirmar que no es hoy poeta y no es artista porque no quiere o porque no consigue libertarse de malsanos prejuicios y de pésimas compañías. No puedo creer que no sepa él, ampliamente, de medida de versos, y de ritmo en toda composición literaria, no digo ya en toda composición versificada. No creo que lo ignore, es tan fácil aprenderlo; y Rafael tiene clara inteligencia y rápida comprensión. Respecto de él solo sé decir que los versos que en un certamen del Liceo le premiamos (yo formé parte del jurado) valen mucho, mucho más que todo lo que después ha publicado en pretenciosos librejos y en sonsas revistas alentado por las voces de ignorantes y majaderos. Apenas si en todo ello hay algo que recomendar y aplaudir. (1925, p. 5)

Dos años más tarde de la publicación de estas valoraciones, Rogelio Sotela efectúa una crítica despiadada contra Estrada. Dice de él:

\begin{abstract}
No hay nadie más enconado que ese pobre muchacho. Vive de casualidad, porque ya la bilis pudo haberse agotado. Yo no le doy juicio sobre él porque le pido a usted su obra para juzgarlo, y usted no puede presentarme nada de él. Solo hay "huellas" a ratos... Precisamente cuando no quiere ser "ultraísta" es que resulta medio poeta. Pero padece del mal gravísimo de la irritabilidad y casi diría que de otro mal más grave aún: el de la envidia. (1927, p. 2)
\end{abstract}

Más allá de estos enconos personales, la crítica de los años veinte -anclada en los modelos tradicionales de valoración literaria, cuyos paradigmas seguían la apreciación de que ningún texto podía ser considerado poético si no seguía la normativa clásica en métrica y rítmica-, acusaba de "modernismo" los afanes de Estrada por incumplir los patrones métricos y estróficos en uso. Claramente lo afirma Sotela, cuando dice que a Estrada "le pasó lo que a los caserones que hacen para las películas: parecía de concreto y resultó de paja. Y todo por ese maldito afán de querer parecer "modernista"' (1927, p. 2).

Esta percepción es ampliamente desarrollada por Napoleón Quesada al descalificar el trabajo de Estrada ya no por necedad o malas influencias, sino por seguir el movimiento "modernista". Con esto amplía las acusaciones de Sotela:

\begin{abstract}
Usted alardea de Modernista y yo hace tiempo que predico contra esa literatura que llaman Modernista y que nadie ha sabido definir, pues el término Modernismo no corresponde a algo concreto, de caracteres precisos, de espíritu y de forma propios, inconfundibles; sino a algo borroso, vago, equívoco. [...] Sería injusto afirmar que el Modernismo consiste en la incoherencia, o en lo vulgar tratado con estilo medianamente artificioso, o en el disloque gramatical, o en dar a las palabras un carácter caprichoso, o en la creación de términos raros, para dar apariencia de novedad a las ideas o en la ausencia de medida o ritmo en los versos. (En Vargas-Villalta, 1957, pp. 63-64)
\end{abstract}

Así pues, Quesada le endilga a la poesía de Estrada no solo el hecho de una supuesta vinculación con el modernismo, lo cual para el primero es incorrecto, en tanto la obra estradiana no se puede asociar con dicho movimiento, ya que su incoherencia y dimensión iconoclasta no tienen otra explicación más que la afrenta a la naturaleza del arte: "despreciar -afirma- las leyes del ritmo y de la armonía es ir contra la Naturaleza, contra el arte puro, contra la percepción sana, contra la emoción sincera y noble.” (En Vargas-Villalta, 1957, p. 64), y concluye subrayando los yerros específicos de las creaciones poéticas estradianas: "Estrada está en un error al creer que hay cierto misterio, cierta novedad, cierta intención recóndita, en afirmaciones, negaciones o vaguedades, completamente vulgares, únicamente por la forma meditadamente ingenua y candorosa con que están expresadas." (En Vargas-Villalta, 1957, p. 65).

Resulta interesante que en dicha polémica lo que estaba en juego, desde el punto de vista conceptual era una nueva forma de escritura que en estos documentos se catalogaba de "moderna" o "modernista", evidente error debido a que aún las estéticas vanguardistas no se observaban con claridad en la época, con excepción de la aguda mirada de Carlos Luis Sáenz. Se confundía, y en esto tampoco Estrada tenía claridad, modernismo tardío con 
postmodernismo y vanguardia, circunstancia que obedecía a la falta de un poco de distancia histórica que permitiera efectuar oportunas distinciones historiográficas y sus fijaciones conceptuales. Hay que recordar que fue Rubén Darío quien por primera vez empleó la noción de "modernismo" para referirse a la renovación poética por él encabezada en un artículo de 1880 titulado "La literatura en Centro América"9. A esto hay que agregar la ausencia de una institución de educación universitaria que ofreciera profesionalización en el campo de los estudios literarios. Por ello, quienes ejercían la crítica lo hacían de manera autodidacta y en los espacios que los periódicos y las revistas culturales les ofrecían.

En Costa Rica, no es sino hasta la publicación de En el silencio (1907) de Roberto Brenes Mesén que se observa, con mayor claridad, la propuesta modernista en la poesía. Por ello, en este período de diez años era aún muy difícil de distinguir el modernismo del postmodernismo y las incipientes manifestaciones de la vanguardia.

Tales circunstancias motivaron el empleo indiscriminado y confuso de las nociones de "modernismo", "nueva literatura" o "vanguardismo" entre los críticos y los escritores. Más aún, esta ausencia de claro discernimiento tiene que ver, también, con el hecho de que, generalmente, los textos no constituyen propuestas homogéneas de orden estético, sino procesos de elaboración que muestran las transiciones y ambigüedades de sus épocas. Por ello, en el caso de la obra de Estrada, lo que la constituye es justamente su ambivalencia estética y, consecuentemente, su carácter híbrido, que procura incorporar a la tradición tanto los afanes postmodernistas de desacralización de las estructuras morfosintácticas románticas y modernistas y la reducción de sus dimensiones simbólicas, como los experimentos vanguardistas que se efectuaban tanto en Europa como en América Latina, indagaciones innovadoras e introductorias en la literatura costarricense, las cuales no tienen suficientes continuadores. Salvo en las obras de Max Jiménez, los procedimientos vanguardistas deberán esperar hasta la década de 1940 en la poesía costarricense ${ }^{10}$.

Esta inestabilidad e hibridación de la poesía estradiana, unida a la confusión que tanto en Quesada como en Sotela se presentaba ante el afán del autor de Canciones y ensayos de deslegitimar los modelos ortodoxos del modernismo, y, más aún, con el desconocimiento de la mayor parte de la ciudad letrada nacional de las tendencias vanguardistas, provocaron el repudio de sus obras y la descalificación por la vía biográfica, aludiendo más que todo a la asociación juventud / inmadurez / desconocimiento de los valores "verdaderos" de la poesía, los cuales, confiesa Sotela, tampoco ve claramente en el movimiento modernista de finales de la década de 1920, sino "algo borroso, vago, equívoco", que equivalía a las pugnas entre los modelos estables (desde los puntos de vista morfosintáctico y simbólico) del modernismo de finales del XIX y principios del XX y las variantes postmodernistas del momento en que escribe estas críticas.

Tales valores no eran otros que los que les asignaba la distinción del joven campo literario costarricense, la cual habían convertido los agentes con mayor capital simbólico (tal es el caso de Quesada y Sotela) en su illusio. Estos valores estaban asociados con la poesía romántica y la modernista ortodoxa de finales del siglo XIX y con las estructuras rítmicas y métricas heredadas de la tradición clásica y las poéticas normativas. Por las limitaciones del incipiente campo, no era una comprensión histórica que permitía considerar la literatura como práctica textual que se realizaba en procesos, sino, por el contrario, la noción de lo literario que se manejaba en la época consistía en un cúmulo de conceptos esenciales que comportaban ideales estéticos orientados a defender la tradición y la dimensión del genio personal. 
Justamente, estos son los supuestos sobre los que descansaban los principios de distinción e illusio de Quesada y Sotela, al mismo tiempo que ello justificaba sus críticas hacia Estrada y sus reclamos de que el autor "no es poeta".

Estrada fue visto por estos agentes como una amenaza del orden establecido en el campo literario. Al defender los principios esencialistas de una única forma de literatura, ambos críticos trasladaron los cuestionamientos al ámbito prescriptivo (solo hay una forma de escribir) y al personal (Estrada no sabe lo que hace). El autor de Huellas, ante tales cuestionamientos, no se quedó solo en el ámbito de la demostración objetiva, sino que asimismo recurrió al ataque personal ${ }^{11}$, cayendo en la provocación e incitando a las diatribas él mismo también.

Esta coyuntura, en la cual estaban en cuestionamiento los modelos romántico y modernista ortodoxo por las estéticas postmodernistas y las orientaciones de las vanguardias, lo que producía textualidades híbridas y heterogéneas, explica, también, el hecho de que se viera esta década de 1920 como un período de decadencia de la literatura del país. En un artículo publicado en La Nueva Prensa, el 23 de setiembre de 1927, y titulado "La decadencia de nuestra literatura", alguien que empleó el pseudónimo de Don Cándido Revoltoso solicitaba que los psicólogos estudiaran "la razón de la pereza intelectual que padecen nuestros escritores." (1927, p. 6). Un contexto donde apenas se distinguía el modernismo y la literatura experimental daba sus primeros pasos, era visto con desesperanza, sin la solidez y densidad de un movimiento intelectual estable.

El mismo Estrada observa el medio "en una desolación muy poco edificante" (1927, p. 11), pero debido al hecho de que se rechazaba incluso las nuevas posibilidades métricas. Ante ello, se dedicó a esa infructuosa búsqueda de la legitimidad de la nueva poesía. En ese mismo año de 1927, cuando intentaba educar el gusto estético de sus coterráneos, dice con gran acuciosidad que aún no distingue claramente en qué consiste la poesía moderna: "No podría yo afirmar que todos los versos modernistas tienen medida. Porque, si la tienen todos, yo ignoro cuál sea. En cambio, conozco la medida de muchos de los versos modernos, y deseara conocer las reglas que ignoro y que a no dudarlo no han sido precisadas todavía, porque las últimas escuelas literarias no han llegado a su debida madurez." (1927, p. 3). Por supuesto, Estrada trabaja, junto con muchos otros autores latinoamericanos, en ese proceso de construcción de la poesía postmodernista y de vanguardia, términos que aún su época no poseía ${ }^{12}$, y por lo cual al "modernismo" se le asignan varios e imprecisos significados.

Tales certezas lo alientan para continuar sus búsquedas. Con mucha claridad de que lo que estaba ocurriendo era una transformación estética, le replica al poeta José María Alfaro Cooper: "Lo de 'Modernismo' Maestro, es un palabra genérica, no específica: aun cuando sus realizaciones son múltiples y muchas de ellas escapan a mi comprensión y no son de mi agrado, veo en ellas un estado de espíritu en transición ascendente que me gusta mucho estudiar." (1929, p. 14).

Luego de haber publicado Estrada su libro Canciones y ensayos en 1929, se preguntó Eduardo Uribe cuáles habían sido sus logros en todo ese desgastante esfuerzo, y contestó que el autor "Tuvo la imperdonable osadía de lanzar un guijarro de su honda al árbol de la tradición y los sañudos loros académicos se alborotaron en alharaca zumbona.” (1934, p. 357). Y un año después de la prematura muerte de Estrada, el mismo crítico argentino se lamentó del estrecho medio que le cerró las puertas al poeta. Rememora que cuando el autor publicó Huellas "No había crítica responsable; no existían periódicos ni revistas literarias; se ignoraban por 
completo las nuevas tendencias artísticas de la postguerra; pero en cambio rendíase culto a fetiches retóricos." (1934, p. 15).

Pero más allá de su sistemática provocación, Estrada tuvo el mérito de aportar pruebas de la existencia de un conjunto de procesos literarios desconocidos para su momento, además de legar una obra experimental, híbrida y densa a la historia literaria costarricense. Esto a la par de haber sido el introductor de la vanguardia poética en el país.

La crítica posterior a su época, tampoco ha sido muy favorable para el autor. Aunque ha habido criterios a su favor, estos han sido los menos. Por ejemplo, Abelardo Bonilla también descalificó la obra de Estrada. Indicó que en los libros del poeta "encontramos la introducción de nuevas estructuras estróficas y rítmicas, algunas revitalizaciones de formas antiguas y ensayos técnicos, pero escasa profundidad poética" (1984, p. 192), en fin, un ejercicio donde "Lo revolucionario no aparece" (1984, p. 193).

Alberto Baeza Flores, por su parte, se hace eco de quienes criticaban la poesía de Estrada, por su cercanía con las vanguardias. La califica de ser "demasiado rígida, un tanto fría y quiere sorprendernos con un realismo demasiado ceñido.” (1978, p. 144).

En otro orden valorativo, Carlos Francisco Monge, sostiene que Estrada "se formó en la tradición modernista, aunque en su poesía es notable una voluntad de emanciparse de la influencia de sus maestros" (2005, p. 59), por lo que lo cataloga como "un posmodernista cuya breve obra poética habla de su pueblo natal, desde una visión impresionista pero liberada de la parafernalia verbal que sedujo a la generación precedente." (2005, pp. 59-60) ${ }^{13}$.

El predominio de los criterios negativos ha provocado que la obra de Estrada se haya condenado al olvido. No estudiada y en textos de reducida circulación, la poesía estradiana figura prácticamente solo en el recuerdo, situación que la crítica costarricense está en la obligación de corregir, puesto que los procesos de hibridación textual que efectúa Estrada proyectan complejos imaginarios de la modernidad literaria costarricense en su etapa fundacional.

\section{Las representaciones de lo moderno}

Desde Huellas, ese imaginario heterogéneo integra tanto los arduos esfuerzos de renovación del modernismo ortodoxo, aquel de finales del siglo XIX, en cuanto búsqueda de relaciones formales entre los versos no sujetas al canon estricto de las fórmulas consonantes, como las exploraciones filosóficas sobre el sujeto y su lugar en el mundo. En este poemario inaugural, se presenta tal indagación por medio de una metafísica que procura explicar las condiciones subjetivas frente al milagro de la naturaleza: "Silencio. Se adivina armonía: / el agua de la aurora cae en el agua negra. / Revive contornos, trae la luz del día; /es la aurora, que alegra con lo que desintegra." (1923, p. 89).

Asimismo, la poesía primera de Estrada ofrece un universo deudor de los tópicos y temas tradicionales de la lírica trascendentalista, pero existen puertas que se abren a la representación del mundo moderno. Allí, toma lugar, por ejemplo, el ajetreo de la ciudad, que alterna, en un proceso de hibridación, con la tranquilidad del espíritu. Uno de los textos más sugerentes, en este sentido, es "Vigilia":

\footnotetext{
Se oyen a la distancia

los cantos de los gallos que estorban el silencio de la media noche.
} 


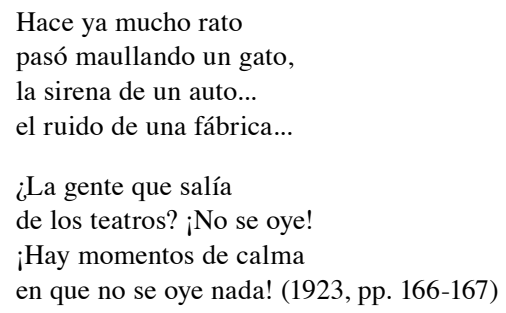

También el acto reflexivo pone en contacto dos universos irreconciliables en la poesía modernista de las décadas iniciales del siglo XX: la subjetividad y el maquinismo, donde la primera es la antesala de la descripción del segundo, fenómeno propio de la lírica vanguardista. En el poema "XXXIX" de Huellas, se cumple a cabalidad con lo que dice Raúl Bueno sobre los modelos de representación vanguardistas que se expresan en locus enunciativos donde la modernidad era más que nada una aspiración. Señala el crítico que un sector muy significativo de la vanguardia hispanoamericana "figuró una modernidad simbólica que solucionaba varias carencias e insatisfacciones de la realidad de su tiempo, comenzando por las que tenían que ver con la ausencia de elementos materiales" (1998, p. 25). En este aspecto, la vanguardia hizo funcionar el maquinismo como metáfora moderna. Dice el poema de Estrada:

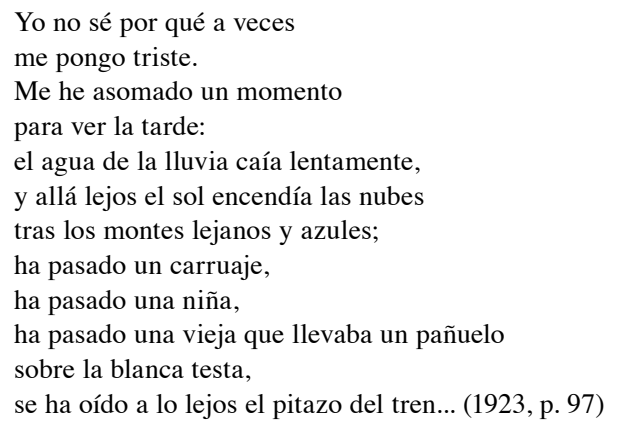

Maquinismo que en este poema no posee una representación homogénea, sino que se encuentra unido a los sistemas de construcción de la realidad del postmodernismo: el intimismo de un sujeto que se halla en el mundo cotidiano y lo describe como escenario que exhibe un estado anímico de tristeza. Alejado de las grandilocuencias del primer modernismo, este poema introduce, al mismo tiempo, en ese paisaje campestre y de desolación espiritual, la figura del tren, símbolo de una modernidad que está a la vuelta de la esquina y que era valorada de una manera ambivalente: en tanto signo del progreso y, al mismo tiempo, como destructora de las tradiciones más arraigadas.

En el segundo poemario de Estrada, Viajes sentimentales (1924), la evidente distancia con las regulaciones métricas modernistas es aún más marcada. Dicho texto, que se aproxima a la narratividad y que refiere a un viaje de retorno del hablante lírico a su ciudad de la niñez, se convierte en lugar de rememoración y nostalgia por el pasado. Pero dentro de su imaginería se halla el espacio para mostrar ese deseo de lo moderno: "las blancas nubes fingen ángeles o muñecos, / y el disco de la luna, y las estrellas, huecos / son de un fantástico traje que han roto las malas / palabras, la malas notas, que son como balas, / que salen, disparadas quién sabe contra quién..." (1924, p. 40).

En este poemario se evidencia una clara conciencia de esa metaforización del mundo moderno. Ya asentada está la intención de multiplicar en los textos "los índices de actualidad" 
(Yurkievich, 1982, p. 352), lo cual se concretiza, mediante la explotación de la imagen del tren, sinécdoque de dicho maquinismo de la era contemporánea, reiterado tópico vanguardista.

Esta construcción está claramente amplificada en el último poemario del autor: Canciones y ensayos (1929), donde, por ejemplo, el texto "La canción del sueño roto de pronto" se vuelve ejemplificador. En él, el enunciador presenta una desordenada conciencia que, desde variadas imágenes representacionales, refiere trozos de un sueño roto, donde la ilación se torna un esfuerzo de la organización discursiva:

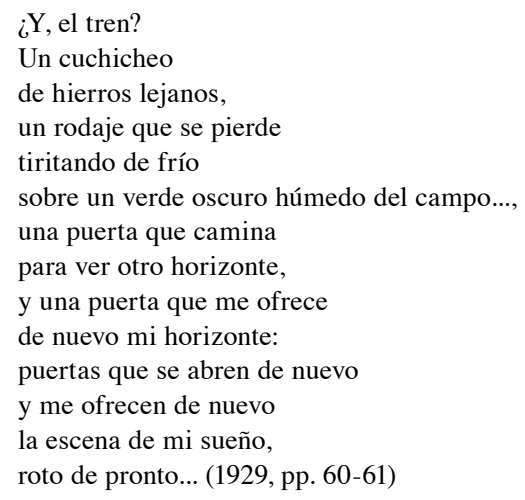

En este texto queda claro, además del énfasis por el maquinismo, otros deseos de esa estética. ¿Cómo no leer las marcas de un fragmentarismo consciente y de la mirada al subconsciente por la vía del sueño? Sin lugar a dudas, estamos en presencia de los orígenes de la poesía de vanguardia en la literatura costarricense, la cual establece vínculos con la estética postmodernista y su carácter intimista.

\section{Conclusión}

Con razón señalaba Carlos Rafael Duverrán, en el trabajo citado al inicio de este artículo, la "libertad postmodernista" de la escritura de Rafael Estrada, si con ello entendemos una literatura heterogénea que asumía como principio la hibridación entre las formas constructivas de la tradición y las propuestas renovadoras, tanto del intimismo postmodernista como de las vanguardias. Hay que agregar a ello los vínculos de Estrada con el pensamiento que defendía la subjetividad en tanto condición suprema de la relación del ser humano con su entorno natural y social. Estas determinaciones de la obra estradiana, lejos de conducir a una poesía signada por su "pobreza lírica" y a una literatura "inmadura", articularon una producción textual híbrida, heterogénea, que supo dialogar con la tradición modernista y alejarse de ella por medio de los intereses representacionales postmodernistas y de los principios vanguardistas de concepción de la modernidad. También, está presente en esta poesía una concienzuda búsqueda de las condiciones subjetivas de una voz lírica que explora en las condiciones existenciales del ser humano que habitaba el complejo mundo social de la Costa Rica de las primeras décadas del siglo XX.

Esta condición híbrida de la poesía estradiana condujo a su condena por parte de los agentes con mayor capital simbólico del campo literario de su época, quienes veían a Estrada como un sujeto advenedizo cuyos escritos cuestionaban y contradecían sus criterios estéticos, así como sus valores de distinción y la illusio que de ellos se generaba. Al enfrentarlos aguerridamente Estrada, se produjo un enfrentamiento por dichos valores que estuvo presente 
tanto a lo interno del campo literario, es decir, se discutió sobre la formas de escritura, así como también a lo externo del campo, dicho sea, se pugnó acerca del prestigio y la autoridad de los capitales simbólicos en juego. En esta lucha desigual entre el centro y la periferia, Estrada y su obra fueron relegados a una zona marginal del mencionado campo literario, lo cual se vio sellado por la temprana desaparición del autor.

Sin embargo, este desplazamiento y relegación no solo fueron fruto de aquella acalorada disputa, sino también de la posterior institucionalidad literaria costarricense, la cual, en su mayor parte, ha seguido ignorando la compleja y densa obra estradiana, relegándola al olvido y dejándola tan solo como un punto de referencia para el estudio de los inicios de la poesía contemporánea.

La poesía de Rafael Estrada Carvajal, ese joven iconoclasta que sacudió el recatado campo cultural costarricense de la segunda década del siglo XX, sigue teniendo la vitalidad de sus disputas, sus experimentos, y sus propuestas. Es una red de textualidades compleja y profunda que está a la espera de salir del olvido.

\section{Notas}

1. Se trata de la tercera sección de su poemario Canciones y ensayos (1929), titulada "Recuerdos de México".

2. Tanto Abelardo Bonilla (1984, p. 192) como Margarita Rojas y Flora Ovares (1995, p. 148) consignan el año 1934 como la fecha de fallecimiento de Estrada. Sin embargo, en el periódico La Tribuna del viernes 29 de diciembre de 1933 se publicó una noticia necrológica que indica: "Ayer a las 10 de la mañana en la ciudad de Heredia se efectuaron los funerales del Lic. don Rafael Estrada cuya prematura desaparición ha sido hondamente lamentada." (1933, p. 2). Con base en esta noticia, es posible determinar que la muerte del poeta ocurrió el miércoles 27 de diciembre de 1933.

3. Un aviso publicado en el periódico La Nueva Prensa, el viernes 7 de mayo de 1926, informa del nombramiento de Estrada en ese mes como profesor de la distinguida institución. Véase: Sin autor (1926). "Profesor de psicología y lógica". La Nueva Prensa. 5 (1412), 7.

4. Moisés Vincenzi (1895-1964) fue uno de los filósofos costarricenses más destacados de la primera mitad del siglo XX. En este campo escribió, entre otros textos, Aticismos tropicales (1918), Crítica trascendental (1920), Diálogos filosóficos (1924), Principios de crítica filosófica (1928), Mi segunda dimensión (1928), La nueva razón (1932) y El hombre máquina (1938). En el campo de la literatura publicó las novelas: Atlante (1924), La Rosalía (1931), Pierre de Monval (1935) y La señorita Rodiet (1936).

5. Villalobos fue un escritor contemporáneo de Estrada, autor de Frisos y columnas (1923), Burbujas de oro (1925), Crítica americana (1925) y Filosofía de vanguardia en América (1927). Al igual que Estrada, fue amigo de Vincenzi y un convencido de la necesidad de renovar las formas estéticas.

6. De la Cruz hace explícito qué considera como poesía: “Tratemos de entendernos primero en este punto esencial: ¿qué es verso? No busquemos definiciones académicas; apelemos a una que sea comprensible para todos: Un género literario que, armoniosamente, cante bellas y nobles ideas. Y eso desde Homero y más allá hasta Aquileo J. Echeverría. Porque si ni hay armonía ni se cantan bellos y nobles pensamientos, el verso no se simula con una mala prosa dividida en renglones cortos." (1924, p. 3). Como se observa, De la Cruz plantea como literatura poética la clásica concepción que asimila el hecho literario con la verdad, la bondad y la belleza, herencia de la tradición grecolatina que estimaba esta tríada como un supuesto esencialista de orden normativo. Al incumplir la estética de Estrada este ordenamiento, el crítico rechaza, estupefacto, la posibilidad de admitir dentro del canon poético la producción estradiana.

7. Otro caso de este tipo de publicaciones que procuraban ridiculizar a Estrada es el texto "Huellas de un Viaje sentimental o un loco hace ciento", suscrito por Manolito y publicado en La Tribuna en marzo de 1924. Unos fragmentos del texto dicen: “¡Oh hijo espiritual de Vincenzi el filósofo! / He seguido tus Huellas paso a paso y encuentro / que los gases poéticos de tu numen teósofo / surgen trepidatorios del fondo al epicentro. [...] Algo me infunden esos, aquellos montes, esto, / no hay duda, es terremoto 
mental, el sol se esconde, / los vientos juguetones, hasta llenar mi cesto, / me llevan por la senda del Arte no sé dónde." (1924, p. 4). Iguales intenciones plantea el texto "Alta poesía", publicado por "don Fulano de Tal" en la revista Bohemia, también en marzo de 1924. Dedica el autor su poema a "Chocano, con permiso de Rafaelillo Estrada", y usando un lenguaje obsceno pretende equiparar su expresión con la de Estrada, en clara burla de los señalamientos hechos por Vincenzi, en el sentido de que la poesía estradiana posee hondas resonancias filosóficas: "Quisiera ser un sapo sandunguero / que saliendo de fétido agujero, / se transformara al punto en vil dinero / pa pagarle al casero, / al chino lavandero, / al lechero / y a la niña aquella del barbero, / pa que me cuesa el güeco fiero / que m'icieron ayer en el trasero / esrotándome el calzón que yo venero!!! [...] ¡¡Oh qué dulces querellas!! / Son más bellas / que las innúmeras estrellas / que líquido en botellas / me hagan mirar en ellas... / Aquí quedan mis Güellas." (1924, p. 14).

8. Cabe recordar que dicho campo se comienza a articular con relativa autonomía entre 1890 y 1910 , cuando se editan una serie de textos que comienzan a configurar la literatura nacional: Máximo Fernández da a conocer la antología La lira costarricense (1890), Carlos Gagini estrena Los pretendientes (1890), Ricardo Fernández Guardia publica Hojarasca (1894). En 1895 se publica "Nochebuena", el primer cuento de Magón. Entre 1898 y 1900 se dan a conocer las obras históricas y literarias de Manuel Argüello Mora y también en 1900 se publica El Moto de Joaquín García Monge. En la década siguiente se continúan publicando los primeros clásicos de la literatura costarricense y se consolidan escuelas y discursos literarios. Véase al respecto, Quesada-Soto (1995), p. 93 y siguientes.

9. Consúltese: Rubén Darío. (1934). La literatura en Centro América. Obras desconocidas de Rubén Darío. Edición de Raúl Silva Castro. (186-212). Santiago: Prensas de la Universidad de Chile.

10. Véase, al respecto, Carlos Francisco Monge. (1992). Estudio preliminar. Antología crítica de la poesía de Costa Rica. (9-35) San José: Editorial de la Universidad de Costa Rica.

11. Cuando en un artículo de 1927 se refiere a Rogelio Sotela, dice: "Y de Sotela ni hablemos, que podríamos ponerlo como padre del charlatanismo y de la farsa que con tanto provecho ha imitado." (1927, p. 11).

12. Para el término "postmodernismo" en poesía, consúltese: Federico de Onís. (1934). Introducción. Antología de la poesía española e hispanoamericana (13-24). Madrid: Casa Editorial Hernando. Es en esta introducción donde el crítico plantea, por primera vez, este concepto historiográfico. La noción de vanguardia en literatura se comienza a emplear en las primeras décadas del siglo XX en Europa. En Costa Rica, indica Carlos Francisco Monge, a pesar de que en fechas tan tempranas como 1904 en que Domingo Monge escribe en Pandemónium un artículo titulado "Apuntes sobre la libertad del arte", y en 1909 Guillermo Andreve publicó en Páginas Ilustradas el trabajo "El Futurismo", la literatura costarricense "apenas tomó nota de la novedad" (2005, p. 17).

13. En su Antología crítica de la poesía en Costa Rica (1992), ya había señalado Monge la adscripción de la obra de Estrada al postmodernismo, movimiento considerado hijo del modernismo, que el crítico ubica entre 1920 y 1945. Señala como sus autores más representativos, además de Estrada, a Arturo Agüero Chaves, Carlos Luis Sáenz, Asdrúbal Villalobos y Fernando Centeno Güell. Como características del movimiento, señala Monge la renuncia al cosmopolitismo y la introspección existencial, que da como resultado un discurso poético centrado en los siguientes elementos: "énfasis en la expresividad de una emoción personal; la fuerte mediatización por la subjetividad de la realidad referida [...] y por las emociones instantáneas (lo efímero es uno de los temas frecuentes); la religiosidad como gesto de reencuentro con las raíces culturales de un pueblo.” (1992, p. 21). También en La rama de fresno (1999), argumenta Monge la condición de puente del postmodernismo entre el modernismo y la vanguardia (1999, p. 71). Margarita Rojas y Flora Ovares se suman a este criterio de Monge en su estudio 100 años de literatura costarricense (1995, p. 101).

\section{Bibliografía}

Baeza-Flores, A. (1978). Evolución de la poesía costarricense. San José: Editorial Costa Rica. Bonilla, A. (1984). Historia de la literatura costarricense. San José: Editorial Stvdivm. 
Bourdieu, P. (1995). Las reglas del arte. Génesis y estructura del campo literario. (T. Kaus, tr.). Barcelona: Anagrama.

Bourdieu, P. (1998). La distinción. Criterios y bases sociales del gusto. (Ma. del C. Ruiz de Elvira, tr.). Madrid: Taurus.

Bueno, R. (1998). La máquina como metáfora de modernización en la vanguardia latinoamericana. Revista de Crítica Literaria Latinoamericana. 24 (48), 25-37.

Cruz, P. (1924, 17 de febrero). Examen y crítica de ingenios. Diario de Costa Rica. 5 (1331), 2.

Darío, R. (1934). La literatura en Centro América. Obras desconocidas de Rubén Darío. Por R. Silva-Castro (Ed.). (186-212). Santiago: Prensas de la Universidad de Chile.

De la Cruz, J. (1924, 14 de febrero). Don Rafael Estrada y su libro Huellas. Diario de Costa Rica. 5 (1378), 3.

De Onís, F. (1934). Introducción. Antología de la poesía española e hispanoamericana. (1324). Madrid: Casa Editorial Hernando.

De Tal, F. (1924, 27 de enero). Alta poesía. Bohemia. 3 (52), 14.

Duverrán, C. R. (1979). Notas para una reseña de la literatura costarricense. Letras. 2, 187-220.

Estrada, R. (1923). Huellas. San José: Editorial Borrasé Hermanos.

Estrada, R. (1924). Viajes sentimentales. San José: Imprenta Trejos Hermanos.

Estrada R. (1924, 4 de abril). De la farándula diaria. Diario del Comercio. 4 (1067), 5.

Estrada, R. (1924, 6 de mayo). Se menosprecian versos de Juan Ramón Jiménez pensando que son de Rafael Estrada. La Tribuna. 4 (1224), 7.

Estrada, R. (1927, 22 de setiembre). El poeta Estrada se refiere a nuestro medio literario. La Nueva Prensa. 6 (1832), 11.

Estrada, R. (1927, 3 de noviembre). El poeta Estrada lanza un desafío a los literatos del país que adversan el modernismo. La Tribuna. 8 (2232), 2.

Estrada, R. (1927, 23 de noviembre). Métrica moderna. Primeros ejemplos para el conocimiento de la técnica de la poesía contemporánea. Diario de Costa Rica. 9 (2516), 3.

Estrada, R. (1929). Canciones y ensayos. San José: Ediciones del Convivio.

Estrada, R. (1929, 17 de junio). Cordiales cartas cruzadas entre el decano de nuestros poetas, don José María Alfaro Cooper y el joven poeta modernista, don Rafael Estrada. La Nueva Prensa. 8 (2254), 14.

Manolito. (1924, 16 de marzo). Huellas de un Viaje sentimental o un loco hace ciento. La Tribuna. 4 (1186), 4.

Monge, C. F. (1992). Antología crítica de la poesía en Costa Rica. San José: Editorial de la Universidad de Costa Rica.

Monge, C. F. (1999). La rama de fresno. Heredia: Editorial de la Universidad Nacional.

Monge, C. F. (2005). El vanguardismo literario en Costa Rica. Heredia: Editorial de la Universidad Nacional. 
Penélope. (1924, 17 de febrero). Huellas de la semana. La Tribuna. 5 (1381), 10.

Quesada, N. (1925, 25 de agosto). Algunas consideraciones sobre poesía contemporánea costarricense. La Opinión. 5 (1475), 5.

Quesada-Soto, A. (1995). La formación de la narrativa nacional costarricense (1890-1910). San José: Editorial de la Universidad de Costa Rica.

Revoltoso, C. (1927, 23 de setiembre). La decadencia de nuestra literatura. La Nueva Prensa. 6 (1833), 6 .

Rojas, M. y Ovares, F. (1995). 100 años de literatura costarricense. San José: Farben.

Sáenz, C. L. (1922, 9 de octubre). Rafael Estrada. Repertorio Americano. 5 (1), 4.

Sin autor. (1927, 28 de setiembre). El poeta don Rogelio Sotela nos da un segundo reportaje. La Nueva Prensa. 6 (1837), 2.

Sin autor. (1933, 29 de diciembre). El fallecimiento del Lic. Don Rafael Estrada. La Tribuna. 3 (3953), 2.

Sin autor. (1926, 7 de mayo). Profesor de psicología y lógica. La Nueva Prensa. 5 (1412), 7.

Vargas-Villalta, M. J. (1957). La personalidad y la poesía de Rafael Estrada. (Tesis de licenciatura). Universidad de Costa Rica.

Uribe, E. (1929, 14 de diciembre). Canciones y ensayos de Rafael Estrada. Repertorio Americano. 11 (471), 357.

Uribe, E. (1934, 7 de julio). Rafael Estrada. Repertorio Americano. 16 (689), 15.

Villalobos, J. F. (1924, 9 de febrero). Rafael Estrada C. Su libro "Huellas". Diario del Comercio. 4 (1023), 2.

Vincenzi, M. (1924, 16 de febrero). Carta a Rafael Estrada. Diario de Costa Rica. 5 (1380), 7. Yurkievich, S. (1982). Los avatares de la vanguardia. Revista Iberoamericana. 48 (118), 351-366. 
